\title{
Amadeus
} International Multidisciplinary Journal IISSN 2525-8281

\section{SOCIAL PANIC DISORDER AND ITS IMPACTS}

\section{Marianna Leite Barrosol Thercia Lucena Grangeiro Maranhão $^{2 ;}$}

Hermes Melo Teixeira Batista ${ }^{3}$ Fernanda Pereira de Brito

Neves ${ }^{4}$

Gislene Farias de Oliveira ${ }^{5}$

\begin{abstract}
Panic disorder has been increasingly focused on health services and the media, where it affects young people aged 20-40. The incidence of these disorders affects $22 \%$ of the adult world population. Of these, $2.8 \%$ are grouped in severe disorders (schizophrenia, manic-depressive psychosis and severe forms of depression, panic syndrome and obsessive-compulsive disorder) in adults (Stuart, Laraia, 2002). This study aims to identify the risk factors for the development of Panic Disorder (PD), through the literature consulted; analyze the authors' discourse and provide health professionals with the necessary subsidies for prevention and early intervention in the presence of possible signs and symptoms of PD. This is a bibliographic study carried out in libraries, the internet, scientific technical books and monographs. The results evidenced that in Brazil there is still no research that shows the real incidence of people affected with this syndrome. It is hoped that this discourse can guide the work of health professionals - specifically nurses - in the development of the syndrome and provide the means for adequate care directed at the patients and their families.
\end{abstract}

Keywords: Panic Disorder; Risk factors; Intervention; Prevention.

\section{Introduction}

For many scholars, conceptualizing the mental health of an individual is a complex task and involves their experiences. To Costa (2002) mental health is directly related to subjective well-being, self-efficacy perception, autonomy, competence, integration dependency, and self-realization of intellectual and emotional capacities.

\footnotetext{
${ }^{1}$ Graduation in Nursing at the São Vicente de Paula Faculty of Nursing. Master's Degree in Nursing from Federal University of Pernambuco. Contact: mariannaleite_@hotmail.com;

${ }^{2}$ Graduate in Psychology. Master in Health Sciences from ABC-FMABC Medical School. Contact: therciapsicologa@ gmail.com;

${ }^{3}$ Doctor by the Federal University of Ceará. Medical doctor from the Cariri Regional Hospital and Professor at the Faculty of Medicine of Juazeiro do Norte-Estácio. Master's Degree in Health Sciences from the Faculty of Medicine of ABC - SP. Contact: hermesmelo@oi.com.br;

${ }^{4}$ Doctor by the Pernambuco Higher Education Foundation (1989). Medical doctor from the State Ceará Health Secretary and Medical anesthesiologist at the São Vicente de Paulo Hospital and Maternity Hospital. Contact: fpbritoneves@ hotmail.com;

${ }_{5}^{5}$ Psychologist and professor at the Federal University of Cariri. PhD in Social Psychology and Post-Doc in Health Sciences by the ABC-SP Medical School. Contact: gislenefarias@gmail.com.
} 
Mental disorders have often been seen as a deviation from a pre-established pattern of behavior, which is normal, both by society as a whole and by science (Brasil, 2002).

Considering this deviant, the historical solution was to contain and institutionalize them, destroying the bond of communication with family members, employment and making it difficult to reintegrate into society (Brasil, 2002).

There are some hypotheses to determine the occurrences of mental disorders, which according to Reinaldo and Rocha (2002, p.36), "there is the biological hypothesis, learning hypothesis, cognitive hypothesis, psychodynamic hypothesis and the environmental hypothesis." The incidence of these disorders affects $22 \%$ of the adult world population. Of these, $2.8 \%$ are grouped in severe disorders (schizophrenia, manic-depressive psychosis and severe forms of depression, panic syndrome and obsessive-compulsive disorder) in adults (Stuart, Laraia, 2002).

According Talbott et al (1992, p. 156-158), "Panic disorder is characterized by periods of attacks that can occur at any time of its day-to-day life, where they will present and experience the sudden onset of fear, terror, apprehension and a sense of imminent death".

It may also appear slowly and insidiously, with generalized feelings of tension and nervous discomfort, or it may arise abruptly as the abrupt eruption of acute anxiety attacks (Kaplan, 1984).

A panic attack lasts 5 to 20 minutes; when someone has repeated attacks, or feels severe anxiety about having other attacks is called panic disorder carrier. This occurs, concern about the consequences of the attack or a change in behavior because of the attack. There should be several attacks in a period of one month, averaging three attacks; An isolated seizure, however, does not characterize the seizure, the occurrence of only one seizure may be associated with other mental disorders, such as in specific phobias, social phobia, posttraumatic stress disorder, but may also occur with the use of drugs or abstinence from it (Almeida, 2006).

These attacks may or may not be associated with agoraphobia, which according to Almeida (2006, 133-134), "is the unexpected fear of leaving or being in public places or in closed places." To be defined as a panic attack it takes at least four of the following symptoms: dizziness, feeling of insecurity, or fainting; palpitations or accelerated heart rate (tachycardia); Tremor, chills; Sweating; Suffocation; Nausea or abdominal pain; 
Depersonalization; Blush; Chest pain or discomfort; Fear to die; Fear of going crazy or doing something uncontrolled (Talbott et al, 1992 pp. 193-4).

The incidence of this syndrome, according to Griesi (2006), affects $3 \%$ to $4 \%$ of the world's population, in the majority young, in the age group between 21 to 40 years old, being observed a degree of incidence of three women for each man. There are also unusual cases, a small number of cases can start in childhood or after 45 years.

Proper holistic treatment of panic disorder (can include both traditional medicine, psychology and other complementary techniques) and this may prevent the attacks or at least substantially reduce their severity and frequency, bringing significant relief in $70 \%$ to $90 \%$ of people (Griesi, 2006).

Considering that panic syndrome has been strongly emphasized in recent years in countries where research is a priority for all health professionals, due to new cases that have arisen in the various fields of work, because it is a characteristic syndrome of perfectionistic, extremely productive people, at the professional level and for being able to approach health professionals, where the majority fit the above mentioned characteristics, especially with regard to excessive workload, causing stressful moments and not having a significant number of mental health work, referring to this topic and recognizing its importance in the present day, we decided to carry out a study to analyze the discourse of the literature and to contribute with the professionals of the area on the importance of the prevention and the early diagnosis of the panic disorder.

\section{Panic Disorder Definition}

The Panic Disorder (PD), according to Scarpato (2007), is characterized by the occurrence of frequent and unexpected panic attacks. Panic attacks, or crisis, consist of periods of intense anxiety and are accompanied by some specific symptoms. For Gabbard (1998, p 174-8), panic disorder: is also known as an anxiety or anxiety disorder and includes neurotic behaviors in which the prevalent neurotic accidents are the manifestations of permanent distress. Appearing as that determined by the hormone-vegative imbalance.

Gabbard (1998) cites that panic attacks usually start with a fright about some body sensations. These triggering sensations can range from a change in heartbeat, a feeling of loss 3 
of balance, dizziness, shortness of breath, a different palpitation or a tremor and that have as characteristics repetitive and sudden crisis of fear with multiple symptoms and autonomic hyperactivity (manifestations controlled by the autonomic nervous system: tachycardia, dry mouth, tremor, etc.) Panic disorder usually begins after age 20, there is little difference in prevalence between men and women, so in most cases, people who have panic, are young or adults aged 20 to 40 years and they are in the prime of working life (Scarpato, 2007). Bernik (2007) states that most studies agree that the prevalence of anxiety disorders is on average 2 times higher in women than in men (ranging from 2: 1 for obsessive compulsive disorder to 8: 1 for agoraphobia, in the range of 25 to 34 years.

\section{Symptoms or clinical picture for the development of panic disorder}

\section{Patients with anxiety symptoms}

The anxious pictures associated with panic syndrome may be: simple and generalized anxiety and phobic pictures of social phobia; simple; and agoraphobia; in addition to obsessive-compulsive disorders (Ballone, 2005).

\section{Patients with somatic symptoms}

Not all of these symptoms can be present in the crisis, but some will always be. There are more complete and minor crises, with few symptoms, can manifest with exuberant autosomal symptoms, which are determined by the imbalance of the ANS and / or the coexistence of psychosomatic disorders, affecting the various organs or systems, according to the list below (Scarpato, 2007):

A - Cardiology: palpitations, arrhythmias, tachycardias, chest pain; that for Gabbard (1998), these pains are described as burns, swellings, stitches or constrictions, irradiated differently, remembering the angina of the chest; vasoconstrictive or congestive crises (may be generalized or localized to the face, limbs, fingers) are usually accompanied by paraesthesia. 
B - Gastroenterology: abdominal cramps, epigastralgia, constipation and diarrhea; accompanied by gabbard, pharyngeal constriction and the "esophageal bolus".

C - Neurology: paresthesias, anesthesia, tingling, headache, sensory alterations.

D - Otorhino: vertigo, dizziness, tinnitus.

E - General Clinic: shortness of breath, sore throat, feeling faint, weakness of limbs, lack of appetite or increased appetite.

F - Gynecology: pelvic cramps, pain in the relation, menstrual changes.

G - Orthopedics: low back pain, arthralgia, neck pain, neck pain.

H - Psychiatry: irritability, changes in sleep (too much or less), anguish, sadness, fear, insecurity, tendency to stay at home, bad thoughts.

I - Respiratory: the first one is dyspnea, which can be of all types and of all degrees, goes from blocked or wheezing to the asthma attack and, for some authors, until the true allergic asthma crisis; coughing, hiccups, dysphonic or even aphasic crises are also observed (GABBARD, 1998 p-178)

F - Urinary: The crises of "strangury" (that is, bladder stuttering, bladder senility, polyuria, polaciuria) (Gabbard, 1998 p.174-178)

Some of these symptoms are present in the panic crisis, others in the Phobia crisis (mainly social phobia), others in psychogenic pain or somatomorphic disorders. The existence of physical symptoms in emotional patients always requires an adequate clinical evaluation. There is no clinical and laboratory confirmation that physical complaints actually represent some organic disorder. We will be confronted with a picture called somatiform, if there are clinically verified alterations, such as hypertension, tachycardia, digestive ulcer, etc., we will face the psychosomatic disorder associated with panic disorder (Ballone, 2005).

\section{Early Anxiety}

According to Scarpato (2007), one of the characteristics of PD is the person living with great anxiety, in the constant expectation of having a new crisis. This process, called early anxiety, leads many people to avoid certain situations and to restrict their lives to a minimum of activities, and to live in their inmates. Secondary phobic reactions may occur, 
which are usually related to situations in which the person had the first crises (in the elevator, driving, passing through a certain place, etc.). From there, the person begins to associate these situations to the crises. Over time, Panic symptoms tend to occur in other situations as well, but it is very common for a person to continue to fear specific situations, which would accentuate the state of anxiety, triggering new crises.

There is a diagnostic classification of Panic Syndrome with and without agoraphobia, which is a state of anxiety related to being in places or situations where escape or getting help could be difficult if the person has a panic attack. It can include several situations like being alone, being in the crowd, being inside the car, subway or bus, being under an overpass, etc. (Scarpato, 2007).

\section{The Emergence of Scientific Classification}

The first official diagnostic classification of Panic Disorder occurred in 1980 with the publication by the American Psychiatric Association, the DSM III (Diagnostic and Statistical of Mental Disorders, 3rd Edition), now in its fourth edition (DSM IV) (Scarpato, 2007). Panic syndrome is part of so-called anxiety disorders, along with phobias (simple phobia and social phobia), post-traumatic stress disorder, obsessive-compulsive disorder, and generalized anxiety disorder. It is also recognized by the World Health Organization (WHO) and is listed in its International Classification of Diseases (ICD 10) (Scarpato, 2007).

\section{Treatment of panic disorder}

According to Ballone (2005, p. 08), the best results are obtained by a treatment that contemplates all these aims; both the management of crisis, the modification of the person's relationship with his own body, the resumption of the capacity for protection by the bond and the elaboration of the unconscious affective processes that led to panic:

- As a first goal we have, crisis management, we have a wide repertoire of specific techniques, involving respiratory techniques, reorganization of somatic-emotional postures of anxiety, techniques of binocular convergence, directed attention, etc. All these techniques 6 
have a strong efficacy in influencing the brain centers that triggered anxiety and panic responses, reducing the intensity of the seizures. It uses the principle of reverse acting, acting from the periphery to the center of the organism, as has been shown in several recent research on treatment options for panic syndrome:

- As the second goal, we have the integration of bodily sensations, we have exercises with focused attention and resignification of body sensations, recognition of the correlation between somatic postures and psychological states, voluntary management of somaticemotional patterns that maintain the state of pre-organized and active panic in the intervals between crises. These various resources help in familiarizing with the sensations of the body, favoring intimacy with the somatic language that organizes the presence in the world, teaching the person how to influence their internal states and disorganize the somaticemotional patterns that maintain the anxiety and lead to the panic;

- As the third goal, we have focused on the ability to reestablish and sustain the deep connection in the bonds. For this purpose one works by identifying the patterns of the person's bond in all their meaningful relationships. We review the life history of relationships and help reorganize bonding patterns toward more stable relationships that can provide a network of trust and affective exchanges essential for overcoming panic disorder;

- As the fourth goal, we have focused on causal situations, we work with the history of emotional life and the mapping of the transitions, existential crises and pressures that were in process when the PD began. We also need to look at contextual factors where, for example, more stressful environments and moments can contribute. It is essential to be able to identify the unprocessed affects that triggered the disconnection responses and, consequently, precipitated PD.

\section{Medication in DP therapy}

If medical treatment is needed, it should be doubly directed: depression and anxiety. Most general practitioners and non-psychiatrists have chosen, for various reasons, anxiolytics as the first drug option. Among the reasons for this choice are mainly the habit and the lack of knowledge of the use of antidepressants, together with the fact that the anxiolytics provide an 
immediate effect, cutting the crisis immediately. However, knowing that depression may be the psychophysiological basis for panic and anxiety symptoms, the most correct approach would be to start treatment with antidepressants, usually associated with anxiolytics, in the initial phase of treatment (Ballone, 2006).

Table 1 - Suggestion for estimating shorter or longer treatment for PD

\begin{tabular}{|l|ll|}
\hline \multicolumn{1}{|c|}{ LONGER TREATMENT } & \multicolumn{1}{c|}{ BRIEF TREATMENT } \\
\hline - Premorbid personality with downright & - & No personal history of anxiety \\
anxious traits & - & No family history of emotional problems \\
- Family history of emotional problems & - & Presence of important emotional stressors \\
Alcohol or drug abuse to relieve & & related to the onset of the disease \\
symptoms & - & Married or Equivalent \\
- Living alone & - & Start at a younger age \\
- Early age onset & - & Premorbid personality with normal traits \\
- Pre-morbid personality with traits of high & & of concern and consequence \\
level of concern and consequence & - & Full awareness of any emotional conflict \\
- Lack of awareness of eventual emotional & & \\
conflict associated with the disease & & \\
\hline
\end{tabular}

Source: Ballone (2005).

Even after being partially convinced, the patient still refuses treatment. Now the problem is drugs. Some of these patients are reluctant to use medication because of their own fear of panic; they are afraid of drugs, of side effects, of everything. Then they are reluctant to be medicated by the stigma of those who use psychoactive drugs, those horrible drugs that "dope", "vitiate", etc. (Ballone, 2005).

\section{Cognitive Behavior Therapy Techniques}

\section{Respiratory and muscular relaxation}

A technique widely used in anxiety disorders, including PD, consisting of breathing exercises and progressive muscle relaxation, where the patient exercises patterns with deep inspiration and expiration and patterns with ample diaphragmatic breathing, giving him a sense of control over his own body (Andrade et al 2005 p-38). 


\section{Symptomatic desensitization}

The patient is led to think and try to experience the feelings that lead him to trigger symptoms that generate anxiety or to undergo a direct exposure graded to the dreaded objects or situations (Andrade et al., 2005).

\section{Interoceptive exposure}

Exposure occurs when specific responses, such as dizziness, muscle tension, empty head, tachycardia, and suffocation, are triggered by cardiovascular exercise, carbon dioxide inhalation, body-spinning, and hyperventilating (Craske; Barlow, in Guimarães, 2001 p-340).

\section{Cognitive strategies}

According to Barlow and Craske (1993), cognitive restructuring with regard to panic began as an extension of Beck's cognitive model of depression, that is, the model initially used for the treatment of depression was used to specify the area of anxiety disorders. It consists in correcting the bad evaluation of sensations considered as threatening.

\section{The A.C.A.L.M.E-S.E or "Calm Down" Therapy}

The "Calm Down" strategy is an acronym (in portuguese: A.C.A.L.M.E-S.E) that represents an eight-step workout explained by these authors: Letter A: It means accepting anxiety. Letter C: Contemplating things around you instead of looking inside yourself, letting what happens to the body; Letter A: Act as if you have not been anxious. Slow down the pace with which you do things, however, stay active. Letter L: Release the air of the lungs, very slowly, calmly, inspiring little air through the nose and exhaling long and smoothly through the mouth; Letter M: Keep the steps above. Letter E: Examine your thoughts, for you may be anticipating catastrophic things; Letter S: Smile, you made it! It deserves all its credit and all 9 
its recognition. Letter E: Wait for the future with acceptance. Get rid of the magical thought that you are definitely free of your anxiety.

\section{Dysfunctional thinking Log}

Feilstrecker; Hatzenberg; Caminha (2003 p-55) emphasizes that the household chores during which the patient records their dysfunctional thoughts increase the patient's awareness of the flow of thoughts and images that influence their feelings and behaviors.

\section{Distraction technique}

According to Andrade et al. (2005 p-50), strategies such as getting out of the environment, engaging in household chores, declaiming a poem, initiating playful activities with games that require attention, or even initiating a neutral conversation with someone .

\section{Paradoxical Intent}

As an example, individuals who experience panic attacks and fear of dying, are soon set to "let it die." After many attempts, often they find themselves unable to get such a response and then his anxiety decreases. Many find the irrational aspect of their apprehensions, and are encouraged to repeat such an act frequently on certain occasions, at graded levels of panic or anxiety, until they experience little or no symptom (Feilstrecker; Hatzenberg; Caminha, 2003).

\section{Reference therapy}

It corresponds to the use of written material to help patients modify their behavior, their thoughts or feelings: to read about subjects about their disorder, thus understanding the 10 
mechanisms that are present in their clinical picture. In addition to making them feel less isolated by the awareness that other people are facing the same problem (Costa, 1997p-312).

\section{Method}

According to Ross et al. (2002), Rossi (1990) has developed the problem-solving approach (hypothesis) through theoretical references found in books, journals and related literature; and aims to know and analyze the main theoretical contributions in the literature on a particular subject. And for Fachin (1993) apud Costa et al., (2000), refers to the set of human knowledge gathered in works, having as fundamental base to lead the reader to a certain subject and to the production, collection, storage, reproduction, use and communication collected for the performance of the survey.

The study was carried out from November 2006 to June 2007, at university libraries (UEPB, UFPB, UFCG); Internet; scientific technical books; and monographs. The sample consisted of the findings in the discourse of the literature on Panic Disorder(PD), with emphasis on the predisposing factors, clinical picture, diagnosis, treatment and prevention; in depth perspective on the topic. Because it is a bibliographical research, the project was not submitted to the Ethics Committee of the State University of Paraíba. The data were collected through articles published in Internet, Monographs; and citations from Technical Books. The data were discussed by comparing the authors' speech and discussing their content, from the perspective of contributing to nursing in mental health and to health as a whole.

In the definition of Panic Disorder (PD), one author complements the discussion of the other, and always having the same focus, which is the "attack", which characterizes panic. Therefore, these authors cite that this syndrome, in addition to being called the syndrome of anxiety or anxiety, brings the attack as the main indication of an evolution to the disease. It is extremely important for us to know this syndrome, as well as all aspects of its evolution, so that, as professionals, we can identify and know what goes on with our patients, whether they are from a Basic Family Health Unit (BFHU), from some Hospital Sector (HS), or from a Psychosocial Care Unit (PCU). 


\section{How the Panic Syndrome Attack Occurs}

According to Gabbard (1998, pp. 174-8), "these crises usually start with a scare about somebody sensations bringing some sensory changes"; and for Scarpato (2007, p.33) "this crisis starts gradually and can cause triggering sensations in the body". Since this syndrome is characterized by attacks, we must know how they happen. Analyzing the citations, the authors say that when the crisis begins, the organism undergoes several alterations that can cause numerous damages in the life of the patient, among them respiratory, gastrointestinal dysfunctions, among others.

Knowing to identify these attacks leads the nursing professional to a better interpretation and an understanding of what is happening in the patient's body. With this, it becomes more consistent with other professionals, to arrive at a more accurate diagnosis.

On the attacks, Scarpato (2007, p.44), says "that begins after the age of 20 and most of them are women" and Bernik (2007: 82), and also that "the incidence in women is twice as in men and that they are in the range of 20 to 40 years."

According to Neto (2006), research conducted in the United States shows that for every 1000 individuals about 1 to 3 are affected by Panic Disorder (PD). The incidence of this syndrome in the world is very diverse; in developed countries, there are practically the same numbers. In Brazil, the statistics are inconclusive, because there are no figures evidenced in PD surveys, this does not mean that there are no cases or that these cases are insignificant; there is still no national study that shows the incidence or prevalence of diagnosed cases in the country.

In a consultation with the Center of Psycho-Social Support (CAPS) of a certain municipality in the interior of Ceará, it was verified that out of every 100 patients attended, 02 had panic disorder; this shows that in Brazil a national survey has to be done to detect its incidence, showing that this disease needs to be seen as a public health problem, and that we professionals, must take the initiative with competent bodies to investigate actively such situation. 


\section{About symptoms and clinical picture during a panic attack}

According to Gabbard (1998, pp. 174-8), the symptoms are "palpitations, arrhythmias, tachycardias and chest pain" and according to Scarpato (2007, p.33-04) the most common symptoms are: tachycardia, loss the visual focus, shortness of breath, difficulty breathing, tingling, dizziness, dizziness, pain or chest discomfort, fear of losing control, feeling of unreality, depersonalization, fear of going crazy, sweating, tremors, nausea, abdominal discomfort, chills, heat waves, fear of fainting, imminent feeling of death, dry mouth.

The citations clearly demonstrate what is felt by an individual with SP; and under the eyes of nursing, this makes evident what we can find in our work environment; people who have specific symptoms of a particular disease, but actually that symptom is linked to the mind. If there is an association of these symptoms with a real alteration of the organism, we are faced with a psychosomatic disorder associated with panic syndrome.

\section{About the Treatment of Panic Disorder}

A number of attempts can be made to treat panic disorder; according to Ballone (2006, p.15-16):

\footnotetext{
"We must first learn to manage seizures by decreasing the intensity and incidence of symptoms in panic attacks; to modify the relation of the person with the sensations of the own body; reestablish and develop the capacity to create and sustain connections and connections with significant people, which protects them from helplessness and anxiety; and elaborate the psychological processes that were acting when the crises began and that keeps the person in a pre-Panic state."
}

Measures such as these facilitate, first and foremost, the patient's own performance towards therapy, since it increases his understanding and his subsequent ability to fight against it. The involvement of a multidisciplinary team makes the most effective treatment before such cases; where the nurse, the psychologist and the doctor; with integrated operations achieve more effective results.

The treatment of the syndrome is part of the drug therapy, which in many cases has an indispensable participation. Ballone (2006, p.15-16) mentions that "the patient should know 
that anxiety and physical symptoms will disappear with treatment and that the base will always be with antidepressants"; and Scarpato (2007, p. 07), describes that "Although the symptoms gradually disappear after the first month of treatment, the medication should be continued for a long time, at the risk of symptoms reappearing if treatment is discontinued."

In view of this, we can see the importance of such a mechanism in the treatment of the disease, showing that it is a long process, which needs to be followed to the letter, where the patient goes through several moments of doubt as to the effectiveness of the medication, taking it many sometimes the abandonment of it. This is due to the long time it needs to use, as well as other doubts about antidepressants, because many are afraid of dependence and the reactions they may cause.

\section{Additional Alternative Treatments}

Another form of treatment found is not drug, mainly based on cognitive behavioral therapy, which according to Andrade et al (2005), in recent years these alternative therapies have been much sought after due to simpler methods, cheaper than drugs and in many cases easily accessible to the population. In this type, we find respiratory and muscular relaxation, symptomatic desensitization, interoceptive exposure and cognitive strategies.

\section{Concerning prevention}

According to Spinelli (2006, pp. 18-19), "to prevent panic attacks, regular exercise is included to try to improve the quality of life through good nutrition, good relationships with people, and good ability to release and tensions ". It is necessary at this time, a multiprofessional interaction with physical educators, nutritionists and psychologists, for a better elaboration in the planning of exercises and in the quality of the food. 


\section{Final considerations}

After the study with the references cited on the subject can be seen the importance given by the authors to the subject and how it shall be handled in our community. As for the expected aims, they have been achieved in part because the literature does not report the situation of Brazil on the issue; however we understand that the panic syndrome is characterized by successive crises, which affects young people, very productive and perfectionists; in the age group of 20 to 40 years, and may or may not be associated with agoraphobia, where treatment for this involves both the drug and cognitive-behavioral pathways; concomitantly with the family support that is essential in its evolution.

It is hoped that these technical and scientific literature findings will stimulate the curiosity of professionals, to carry out further studies on the subject, noting that there is in the country one national study that shows the actual size of the amount of people affected by this syndrome.

For nursing professionals, it is important to know the subject, since according to the literature consulted; new cases emerge every day in the different social groups of the modern world. And as caregivers, we must always be attentive and updated as to the emergence of various pathologies.

\section{References}

Almeida, R.S. (2006) Tratado de psiquiatria. Porto Alegre. Artes médicas.

Andrade, M. F. B.; Macedo, M. L. M.; Guimarães,R. L. L. (2005) Transtorno do pânico: uma visão cognitivo-comportamental. Monografia (Especialização em Psicologia Cognitiva Comportamental). Faculdades Integradas de Patos. João Pessoa.

Ballone G.J. Tratamento da Síndrome do Pânico. Retrieved in 1/08/2007 from www.psiqweb.med.br.

Ballone,G.J. (2002). Síndrome do pânico. Retrieved in 09/20/2006 from http//www.psiqweb.med.br/pantext>.

Barlow, D Craske, D. (1993). Manual clínico psicológicos. Porto Alegre: Artes Médicas. 
Bernik, M.A. Tratamento do transtorno de pânico com antidepressivos tricíclicos. Retrieved in 1/18/2007 from: www.amban.org.br/profissionais/artigos.asp?hyperlink=artigos

Brasil, Memória da loucura. (2002). Retrieved in 5/14/2006 from : http//www.ccs.saude.gov.br/saúde-mental/pdf/informacoes>

Costa, Juares. (2002). A importância da família na saúde mental. Retrieved in 09/22/2006 from http// www.sppc.med.br/mesas/juarescosta.htm>

Costa, M. R. (1997). Introdução à psicoterapia cognitivo-comportamental. João Pessoa: Idéia.

Costa, S.F.G da et al. (2000) Metodologia da Pesquisa - Coletânea de Termos. João Pessoa, Idéia. 105.

Fachin, O. (1993) Fundamentos de metodologia. São Paulo: Atlas.

Feilstrecker; Hatzenberg; Caminha. (2003). Psicoterapias cognitivo-comportamentais: teoria e prática. São Paulo: Casa do psicólogo.

Gabbard, Glen O. (2002). Psiquiatria psicodinâmica. Art Méd. 2 ed. Porto Alegre. 1998.

Gil, A.C. Como delinear estudos de campo. In: Como elaborar projetos de pesquisa. (2002), $4^{\mathrm{a}}$ ed. São Paulo: Atlas.

Griesi, Mônica. A síndrome do pânico. 2006. Retrieved in 01/21/2006 from www.mgriesi.com.br.

Guimarães, S. (2001). Técnicas cognitivas e comportamentais. In: RANGÉ, B.(Org.) Psicoterapias cognitivo-comportamentais: um diálogo com a psiquiatria. Porto Alegre: Artmed.

Kaplan, \& Sadock. (1984). Compendio de psiquiatria dinâmica. Artes médicas. $3^{\mathrm{a}}$ ed. Porto Alegre.

Rangé, B.(2001) Psicoterapia cognitivo-comportamentais: um diálogo com a psiquiatria. Porto Alegre: Art Méd.

Reinaldo,A. M. S; Rocha, R. M.. (2002) Visita domiciliar de enfermagem em saúde mental, idéias para hoje e amanhã. Revista eletrônica de enfermagem. 4(2).

Rossi, R. Metodologia científica para a área da saúde. (1990). São Paulo: Ed. Pancaste.

Scarpato, A. Síndrome do pânico: um tratamento eficaz. Retrieved in 01/10/2007 from www.psicoterapia.psc.br/scarpato/panico.html

Spinelli, E. Síndrome do pânico. 2006. Retrieved in 01/21/2007 from: www.psicoterapia.psc.br/scarpato/panico.html 
Stuart, Gail Wiscarz; Laraia, Michele Teresa. (2002). Enfermagem psiquiátrica. 4 ed. Rio de Janeiro: Reichmann \& Affonso Editores.

Talbott, John et al. Tratado de psiquiatria. (1992). $1^{\text {a }}$ reimpressão. Porto Alegre: Arts Médicas.

\section{How to cite this article (APA format):}

Barroso, Marianna L.; Maranhão, Thércia L. G.; Batista, Hermes M. T.; Neves, Fernanda P. de B. \& Oliveira, Gislene F. de. (2018). Social Panic Disorder and its Impacts. Am Int Mul J, 2(4), 1-17.

Received: $15 / 01 / 2018$.

Accepted: $12 / 03 / 2018$ 